\title{
Effect of Peer Psychological Counseling on Mental Health Education of College Students
}

\author{
Ding Song \\ Guangdong Teachers College of Foreign Language and Arts \\ (Guangdong ,China 510640)
}

Keywords: College students; Psychological counseling; Peer model

\begin{abstract}
In the process of carrying out the education of college students, mental health is the key that can not be ignored, along with the development of students' physical and mental health, in order to cater to the characteristics of mental health of the population, it is imperative to carry out health education in Colleges and universities by peer counseling. In this paper, based on the peer model specification, there is a full analysis of the realistic role guidance mode, and puts forward some suggestions on how to develop the implementation of mental health education to provide reference for mental health education in Colleges and universities.

In the face of increasingly complex psychological problems, in order to better promote the formation of College Students' psychological model into more scientific way, colleges and universities have established a series of psychological health education mode, which is particularly prominent in the peer model. The peer model meets the realistic demand of mental health education, change the past single channel of students' psychological counseling, create conditions for improving the effectiveness of mental health education. Based on this, the paper explains how the peer model affect the students on detail.
\end{abstract}

\section{Essence of Peer Model}

"Peer" is a word in a literal sense, which can be interpreted as friends and peers reflecting the peer is represented by a similar age with similar values and similar experience and showing that the consistency of the group. Peer model is applied to psychological education which mainly refers to that through the training of amateur mental health practitioners, it can help the education mode for the need for mental health counseling peer. Because college students ate group life that can form a close relationship with their peers, and the interaction between students of comfort and persuasion to break the barriers of traditional professional psychological education, with its own unique randomness and kind of identity for the university student, it has the advantage of friendship, initiative, convenience, timeliness.

Friendship is the most important feature of the peer model, the process of college students go into the school by the family from parents protection and to seek comfort through peer, under the atmosphere of study and life, there is similar life experiences among companions, thus forming similar views, finally able to establish strong ties of friendship. The relationship between peer exchanges is easy to overcome the difficulties of mental health education strangers dilemma, establishing counseling relationship to friends as the main path exerts a subtle influence on the students' emotion. The initiative is an important distinction between traditional and unfamiliar peer psychological education, psychological education of the workers engaged in from college students, they are helpful and the personality characteristics of the relationship between students and workers volunteered to help recipients to complete the self adjustment, while not to get the material reward for the purpose which is not driven by the interest[1], only the pursuit of self identity meets that is consistent with the behavior of the public nature of mutual aid.Peer mode mainly depends the construction of the relationship between students, implementation of education exchanges frequently greatly reduces the difficulty of developing psychological education, education of both close contacts can reduce the multiple factors for the mental health education of the obstacles and be broken through the time and place restrictions to education, and psychological counseling can be made smaller outside whenever and wherever possible.In addition, the peer model mostly used by 
college students can carry out psychological counseling case, which is similar to the way of life to build relationships that can be trusted as educator and the educated, which is made up of professional malpractice mode, and people can identify and implement teaching suggestions, visible interaction and improve the efficiency of education.

\section{Existing Problems of Peer Mode}

Although peer mode adapts to the psychological education of college students, but it has to admit that there still are the existing some disadvantages on peer education mode restricting the healthy psychological development of college students, in general, they can be explained as follows.

Pedagogue's quality is not up to standard. The rapid development of college education has made great changes in the psychology of college students, which has put forward higher professional quality requirements for those engaged in education. But due to the lack of college students with mental health practitioners, the professional quality is restricted by the external long-term at a low level, for the mental health education, it is lack of knowledge, and it can not fully grasp the key points and difficulty of peer education, so the actual demand to peer mode development coordination will lead to mental health education that is not to further promote the university students in the face of difficulties and to educators to smooth communication, which do not enjoy psychological counseling that should be the actual effect of peer education can not reach the ideal.

Form of education is thin. The existing peer model is confined to students seeking psychological assistance, lacking of teaching for students' attention, and unable to realize the change from passive to active consultation between help. Taking into account the fragile mentality of college students, the weak form of education is often unable to achieve timely help to the recipients, and it is difficult for college students to solve their psychological problems for the first time. This puts forward new requirements on the teaching form of peer mode and requires educators to take the initiative to seek the popularization in college students in the form of work, the content of education breakthrough plain and vigorously improve the effectiveness of education services.

Subject of education is relatively narrow. The practice of peer education in most is oriented by therapeutic goal, this is limited to the psychological problems of college students psychological counseling, and this relatively simple target will have no doubt education object confined to a small part of the students ignoring the entire group for mental health guidance needs. Almost every students will experience to coordinate their life and interpersonal aspects of the problem, the subject of the peer education should be broad groups of college students, and the education goal should be the prevention of psychological problems by solving psychological ills to improve the mental health of students through the popularization of health knowledge together with the deepening education development model of college students.

\section{Modified Path of Peer Model}

To solve these problems, and to achieve the better for college students' mental health education, scholars should in-depth study about peer mode improvement path. The scheme can be roughly interpreted based on the practice of psychological education of college students that was studied. Secondly, starting from the grasp of the psychological characteristics of the students, continue to expand the implementation path of peer mode, and combine the obstacles of psychological counseling and development of health education, laying the foundation for promoting the development of physical and mental health of college students.

The formation of multi-peer assistance. Class is the basic unit of universities to achieve peer mode, and the class has become the main implementation of mental health education of college students, the class can communicate to find the psychological problems, and effective communication with teachers and parents. The formation of peer multilateral aid requires students have mental health knowledge by taking the initiative to share relevant psychological knowledge actively communicate with other students in the class management, and there are difficulties 
concern students which will reflect the problems related to other organizations engaged in psychological education to active counseling training and improve their overall quality. In addition, associations occupy a dominant position in college students' after school life, and community activities can have a certain impact on college Students' psychological health. The peer model requires community activities to be able to cooperate with the related work of mental health education, for example, to break the restrictions and broaden the community department members of the source, a relatively wide range of community members can provide basis for the establishment of peer mode for college students. In addition, community responsibility is also reflected in playing through lectures on psychological health and psychology films regularly to create a learning environment for the students' psychological health knowledge, and improve the psychological adaptability. With the form of psychological salon, it can alleviate the pressure of college Students' study and emotion and ensure their mental health.

Carrying out extensive forms of activities. The advantages of peer education is changing the natural original mode of psychological education, integrating daily activities to college students' mental health education which can effectively achieve the entertaining. To effectively improve the quality of education will be held theory education course to attract college students to participate in the peer education through psychological games and quizzes to carry out various activities and popular education idea, which can also set up psychological counseling hotline in improving college students' interaction and help the students to release pressure that means encourage college students' psychological adjustment. To carry out peer education of college students, the scope should be extended on the basis of related activities to improve mental health content with diversified teaching prompted groups, and to ensure the organic cooperation of relevant departments, teachers should try to construct the integrated health education network, university classes and psychological education institutions, specific management organizations, each power mutual interaction through creating to daily campus life and psychological education of college students combining goal activities, guiding students to maximize the experience of education subject peer mode regarding a university gardening practice as the case, combining the concept of medical treatment, opening up college students in the green garden design, participating in the campus in the process of planting flowers in the garden with physical and mental relaxation and birds'twitter and fragrance of flowers to help the development of mental health[2].

Improving the teaching ability of teachers. Putting forward certain requirements for the learners ability to peer mode, teachers should vigorously carry out peer educators training to ensure that students get good psychological counseling to create conditions. The training should combine theory and practice, such as the mental health theory and practice peer mutual complementary and crisis prevention to provide theoretical knowledge for teaching, self growth theory of knowledge, and focus on communication skills, observation skills recognition practical knowledge[3], Considering the students for their privacy, in the peer educators training mode, it should highlight the educated group confidentiality of personal privacy, full respect for the individual demands of learners. In order to make the teachers fully adapt to teaching activities of mental health, after the training that should be added to simulate peer education consultation links to ensure that the teaching of practical ability, experience and feelings of concern in simulation education recipients discussed later in the feedback peer education that is implemented to carry out mental health education.

Generally speaking, the peer model have a profound impact on the mental health education in colleges and universities, it not only can compensate for the inherent defects of health education, improve the timeliness of response to the psychological crisis of college students through peer education approach for college students to create mutual comfort and healthy development of channel of psychological helping for college students, and the future development and interpersonal communication providing psychological support. Therefore, to overcome the drawbacks of the existing mode of peer education in colleges and universities, it should increase the teaching training by providing rich and colorful mental activities, broadening the peer education groups to improve 
college students' attention to the organization, and the peer model in college that are thoroughly can promote rapid development of mental health education.

\section{Reference}

[1] Shengfeng Jiang.Peer counseling in college students "psychological health education" in the teaching design[J].Journal of Lanzhou Institute of Education,2013(09):85-86.

[2] Dandan Ji, Lexiang Hao.Peer counseling: a new way of mental health education in Colleges and Universities[J].Journal of Taiyuan Normal University(Social Sciences Edition),2010(03):130-131.

[3] Zhengxin An, Liguo Liu, Mingxuan Wang.Analysis of the role of psychological counseling Station in college students' psychological health education[J].Youth Years,2013(21):176-177. 